\title{
Statistical Detection of Vote Count Fraud (2009 Albanian Parliamentary Election and Benford's Law)
}

\author{
Dorina Bërdufi \\ Political Department \\ Tirana University, Albania \\ E-mail: berdufidorina@gmail.com
}

Doi:10.5901/mjss.2014.v5n2p755

\begin{abstract}
Election fraud is difficult to be detected especially in developing countries undergoing multiple dimensional transitions. The Albanian political actors' mistrust leads to a fraudulent environment for all elections held since 1991 (post-communist regime) being disputed for potential fraud. This paper applies the first digit Benford's Law to the 2009 parliamentary elections results for each of the 12 districts as a way of mapping the disputes for the fraud level during elections. The results and graphs show that there has been an obvious election fraud; there is no correlation between the votes and Benford's rate in almost all the districts. The analysis performed evidences the shift of votes from smaller parties towards the major ones especially towards the Democratic Party and Socialist Integration Movement (2009-13 governmental coalition) and also the swung of votes from the losing coalition (including the Socialist Party as leading party of the governmental opposition) to the wining one. There is evidenced also a shift of votes from the main parties to the smaller ones, probably within the same coalition. The fraud evidenced from Benford's Law (as per figures presented) illustrates that the incurred level has resulted in the alteration of political representative number currently in the Parliament, both at party and coalition level.
\end{abstract}

Keywords: Election Fraud, Benford's Law, parliamentary election results, distribution, correlation;

\section{Introduction}

How do we know that the official winner of the election really won the actual declaimed vote numbers? Are we fully certain that the result wasn't manipulated? The central and local elections are often characterized from a constant debate on manipulation from one party or the other deriving from vote steeling, uncounted votes, disrupting the will of the voters or of the vote counters, purchase of votes etc. The main concern relates to detect and prevent manipulation in advance and take the proper steps to prevent it. The actual practice is place by only looking at electoral results and assume of manipulation based on one side statements is not that trustworthy. The main question that arises in this matter is logical: "Is there a way of measuring if there have been or have been not electoral fraud?"

Free and fair elections are the cornerstone of every democratic society (Diamond LJ, Plattne MF, 2006). Throughout the world, in old and new democracies alike, allegations of vote fraud frequently occur (Lehoucq 2003) (Mebane Jr Walter R., July 17, 2006, pg 1). Accusations of fraud and electoral skullduggery seem an ever-present component of democratic process. Although things may have not changed much historically the winners rejoice, whereas the losers claim foul (Joseph Deckert, Mikhail Myagkov, and Peter C. Ordeshook, 2011, pg. 245). Almost each one of the election results held in Albania (local or parliamentary) have been contested and made doubtfulness of the respective legitimacy. The same has happened in the 2009 parliamentary election: the Union for Change Coalition with its main party, the Socialist Party, claimed fraud of votes. Third part international observers have assessed the vote count negatively in 22 of the 66 Ballot Counting Centers (OSCE/ODIHR, 2009, pg. 24). Moreover, many smaller parties claimed that their votes had been shifted towards the two main parties Democratic or Socialist Party (OSCE/ODIHR, 2009, pg. 26).

Although elections are one of the central pillars of a functioning democracy, little is known how to measure electoral fraud. The issue in this case is that the output is only derived from observing or detecting singular manipulation but it can not be proven or analyzed in a large scale. It would be very appreciable the development of an objective method (statistical) that could measure the election manipulation based on the election offical results. This statistical tool would serve as an indicator, which applied on the election returns, would investigate the election's legitimacy. Some practices of manipulating voting results leave traces, which may be detected by statistical methods. Recently, Benford's 
law (Benford F, 1938, Proc Am Philos Soc 78:551-572) experienced recognition as a potential election fraud detection tool (Mebane Jr., W. R, 2006).

In this paper I apply first digit Benford's Law on the 2009 parliamentary results on the 12 electoral disctrict of Albania and then analize the results and changes between the real data distribution outcome and Benford's Law first digit distribution. The difference of counted votes real data and the statistical distribution based on this Law is created to show if there has been, and if so, at what level.

\subsection{Benford's Law}

Benford's Law is a mathematical distribution statistical theory based on the first leading digit of the numbers presented in a large data set. It states that the probability of the frequency occurrence of the leading digits of a large data set of numbers is not uniformly distributed. The law explains how this could arise if the frequency of first digits themselves were not uniform in real world observations but rather followed the rule (Malcolm Sambridge, Hrvoje Tkal'ci'c and Pierre Arroucau, 2011, pg 1). In a simpler way by illustration, it defines a way that if we randomly select a number from a physical or statistical large data set, the probability that this number leading digit would be 1 is about $30.1 \%$ and attributes a specific percentage weight to each of the first 9 natural number. The other remained numbers starting with others digits come in descending order, such as first digit 2 comes out $17.6 \%$ of the times, and so on by the latest one being the first digit 9 coming out about $4.6 \%$ of the times.

Formally, Benford's Law can be expressed: A set of numbers is said to satisfy Benford's law if the leading digit $d(d \in\{1, \ldots, 9\})$ occurs with probability:

$$
P(d)=\log _{10}(d+1)-\log _{10}(d)=\log _{10}\left(1+\frac{1}{d}\right) .
$$

In the table below are shown the nine first digit numbers and their frequency of occurrence:

Table 1 Benford Law predicted frequencies (1BL)

\begin{tabular}{|l|lllllllllll|}
\hline & 0 & 1 & 2 & 3 & 4 & 5 & 6 & 7 & 8 & 9 & Mean \\
\hline First digit & - & 0.301 & 0.176 & 0.125 & 0.097 & 0.079 & 0.067 & 0.058 & 0.051 & 0.046 & 3.441 \\
\hline
\end{tabular}

\section{Benford's Law application in Vote Counts}

Studies on voting behavior have built models on the base that each individual's choice is essentially a coin flip, and the election results being only the artificial sum of this coin flips taken together. The probability of different voters' outcome is different, meaning that the election coin may have more than two sides. As Mebane argues: "Taking voter turnout decisions into account does not essentially change the basic coin flip idea". In this case, to produce the coin flips probabilities, the probability of each person's vote is multiplied by the conditional probability that the person makes a particular choice among the candidates or ballot initiative options. (Walter R. Mebane, Jr., 2006, pg 4)

The approach of this paper is to apply this statistical theory of the first digit frequency distribution to the electoral outcome of Albanian 2009 parliamentary counted official vote results.

During the last years, Benford's law has been used on the election data set in the fraud evidencing. An example is its use to evidence manipulation in the 2009 Iranian elections (Stephen Battersby, 2009). This method is based on tests of the distribution of the digits in vote counts, so all that is needed are the counted vote counts themselves. (Mebane Jr Walter R., July 17, 2006, pg 1). As "fraud" I assume every kind of manipulation that could have been done during the vote counting process of the Albanian Central Electoral Commission official report results, such as steal of vote, uncounted vote, disrupt the counters will, shifted votes, etc.

I applied this theory on the 2009 Albanian Parliamentary electoral results for each of the 12 electoral districts since based on the Electoral Code of Albania each district functions as an independent electoral zone, and serves as an electoral unit for a specific number of parliamentary mandates (Electoral Code of the Republic of Albania, 2008, 2012). Votes, in 2009, were counted manually from the Local Electoral Commissioners for each of the 12 district. Counting teams were composed of four members nominated by the parliamentary majority and by the opposition, Democratic Party and Socialist Party of Albania. 
Thus if $1 \mathrm{BL}$ will show vote manipulation, most probably this manipulation has been done from these counting commissioners since no one else was allowed to enter the counting zone. In terms of Albanian vote counts, Benford's Law distribution depends on the frequency occurrence size of each political party support treated as a data set for statistical purposes.

My interest in this paper is to confront the real data of official counted vote's distribution of Albanian 2009 election to the 1BL (first digit Benford's Law Distribution), in order to observe if these two distributions do match, or if there have been fraud in the election results. Although, based on the claims of particularly the losing political parties of the Albania 2009 Election and on the not so positive report of OSCE/ODIHR for the 2009 election results, (OSCE/ODIHR, 2009), I do not expect the two forms of distributions to match. Those who are not aware of this theory and intentionally manipulate numbers (for example vote count fraud) are susceptible to get caught by the application of Benford's Law.

Benford's, somewhat surprising law, with its monotonic decreasing first digit distribution, has been demonstrated to hold with a large number of data sets that include the populations of towns, budgetary data of corporations, the number of citations received by papers, and the half-lives of radioactive atoms. (George Judge, Laura Schechter, 2007, pg. 3).

Benford's Law can recognize the probabilities of frequencies of first digit numbers, based on mathematical logarithms of the occurrence of first digits in randomly generated numbers in large data sets. The numbers of the data set taken into consideration from the law are randomly generated. In this case, the number of voters in each district selects a particular number of respective parliamentary representatives can be applied the law.

\section{Benford's Law Application to the Albanian 2009 Parliamentary Vote Counts}

1BL predictions are going to be tested as above mentioned, against the official parliamentary 2009 election data in the attempt to ascertain whether fraud has or has not occurred. As an Albanian district functions as an electoral zone unit, I will analyze them separately.

Important to be mentioned before beginning to analyze the two forms of vote counts distribution, is that the main actors in the Albanian Political arena are the Democratic Party of Albania "PD" (main party of the Changing Alliance Coalition), the Socialist Party of Albania "PS" (main party of the Union for Change Coalition) and the third from the importance is the Socialist Movement for Integration Party "LSI" (main party of the Socialist Movement for Integration Coalition).

\section{1 Berat district 2009 Electoral Results 1BL Analyze}

Table 2 Berat's district 2009 Parliamentary Result

\begin{tabular}{|l|l|l|l|l|}
\hline 1BL & Count & Real Data Rate & Benford Rate & Fraud Measure $\Delta \%$ \\
\hline 1 & 12 & $36.4 \%$ & $30.1 \%$ & $6.3 \%$ \\
\hline 2 & 6 & $18.2 \%$ & $17.6 \%$ & $0.6 \%$ \\
\hline 3 & 4 & $12.1 \%$ & $12.5 \%$ & $-0.4 \%$ \\
\hline 4 & 1 & $3.0 \%$ & $9.7 \%$ & $-6.7 \%$ \\
\hline 5 & - & - & $7.9 \%$ & $-7.9 \%$ \\
\hline 6 & - & - & $6.7 \%$ & $-6.7 \%$ \\
\hline 7 & 2 & $6.1 \%$ & $5.8 \%$ & $0.3 \%$ \\
\hline 8 & 3 & $9.1 \%$ & $5.1 \%$ & $4.0 \%$ \\
\hline 9 & 5 & $15.2 \%$ & $4.6 \%$ & $10.6 \%$ \\
\hline
\end{tabular}

Graph 1 Berat's district 2009 Parliamentary Result

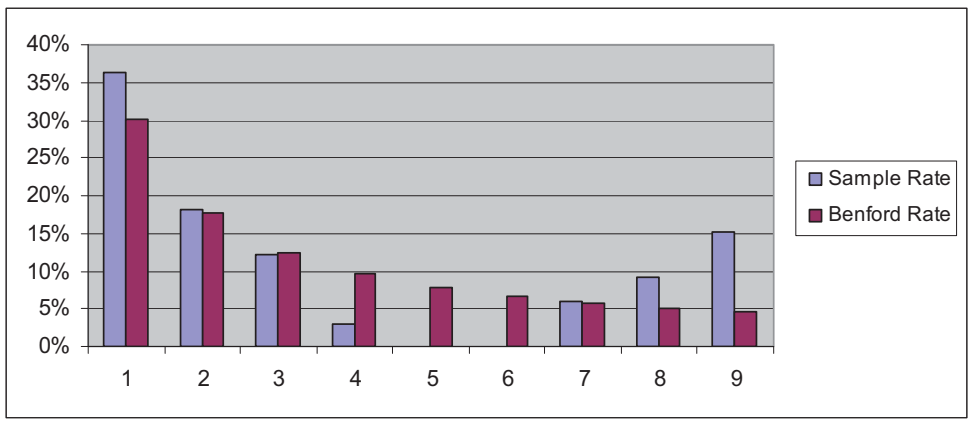


Table 3 Berat's district 2009 Electoral result

\begin{tabular}{|l|l|}
\hline Group of parties based on 1BL had an increase in votes & Group of parties based on 1BL had a decrease of votes \\
\hline 1 (AD, PAA, AMIE, ADS, PFA, LZHK, PBD, PDK, & 4 (PDRESH, PLL) - $6.7 \%$ \\
PRDSH, PMDE, PTR, PBDNJ, PLIDR) $6.3 \%$ & 5 (empty set of data) $-7.9 \%$ \\
2 (BLD, PD, POSH, PRRL, PGJ, PSV 91) $0.6 \%$ & 6 (empty set of data) $-6.7 \%$ \\
8 (LDLNJ, LSI, PDS) 4\% & \\
9 (LDK, PBK, PDI, PKONS, PSD) $10.6 \%$ & \\
\hline
\end{tabular}

Based on the 1BL of vote for the Berat district, from graph 1, it can be seen that there has been fraud; none of the two combined forms of distribution columns correlates to each other. Interesting is the fact that the first digit groups beginning with 5 and 6 are empty data set of votes, which means that there have been full manipulation. Probably, these votes are shifted to other parties (in the left column of table 3). The other group of parties (starting with first digits 4 of votes) that have missing in their counted votes are composed from two political parties that were in coalition with the PD (Changing Alliance). Probably this $-6.7 \%$ have passed to the PD party of group with 2 as first digit vote number group as well as to the other parties that were in this coalition of first digit group 1 and 9 (AD, PAA, AMIE, ADS, PFA, PRDSH, LDK, PBK, $\mathrm{PDI}$ ) as it can be seen from table 3 . The greatest adding of vote percentage over the $1 \mathrm{BL}$ distribution relates group 1 while PD is the leading party of the coalition of PDRESH and PLL.

In the left table column, 12 parties of the Changing Alliance Coalition make $44 \%$ of the total of parties that had an increase in counted votes. It means that this coalition based on 1BL made the most manipulation in its benefit. For itself the PD party is in group 2, with two other parties of its coalition and also three other parties of Socialist Movement for Integration coalition and one of the Freedom Pole Coalition. Their percentage is not too high, only $+0.6 \%$, not to significant compared with the other analyzed above and also not too statistically significant in this case. Instead the LSI party and two parties of the Socialist Party of Albania Coalition, belonging to group 8 , had an increase of $+4 \%$ in the normal distribution of votes as per Benford's Law. Interesting is to analyze the fact that the PS is not present in table 3. Based on 1BL, this party in Berat district has not suffered or performed directly fraud, but indirectly from its coalition member parties LDLNJ, PDS, PBDNJ, and PSD. As, a conclusion, the distribution of first digits of Benford's Law doesn't correspond to the normal distribution of the Berat real election data. In this matter of facts, based on 1BL distribution, predominantly the highest manipulation has been done from the Changing Alliance Coalition smaller members compared to the leading PD party, followed by LSI party. The parties which suffered the loss of votes are difficult to be determined due to the groups of 5 and 6 first digit of vote number being empty data sets.

\subsection{Dibër district 2009 Electoral Results 1BL Analyze}

Table 4 Dibër district 2009 Parliamentary Result

\begin{tabular}{|l|l|l|l|l|}
\hline 1BL & Count & Real Data Rate & Benford Rate & Fraud Measure $\Delta \%$ \\
\hline 1 & 6 & $18.2 \%$ & $30.1 \%$ & $-11.9 \%$ \\
\hline 2 & 9 & $27.3 \%$ & $17.6 \%$ & $9.7 \%$ \\
\hline 3 & 6 & $18.2 \%$ & $12.5 \%$ & $5.7 \%$ \\
\hline 4 & 3 & $9.1 \%$ & $9.7 \%$ & $-0.6 \%$ \\
\hline 5 & 1 & $3.0 \%$ & $7.9 \%$ & $-4.9 \%$ \\
\hline 6 & 2 & $6.1 \%$ & $6.7 \%$ & $-0.6 \%$ \\
\hline 7 & 1 & $3.0 \%$ & $5.8 \%$ & $-2.8 \%$ \\
\hline 8 & - & - & $5.1 \%$ & $-5.1 \%$ \\
\hline 9 & 5 & $15.2 \%$ & $4.6 \%$ & $10.6 \%$ \\
\hline
\end{tabular}

Graph 2 Dibër district 2009 Parliamentary Result

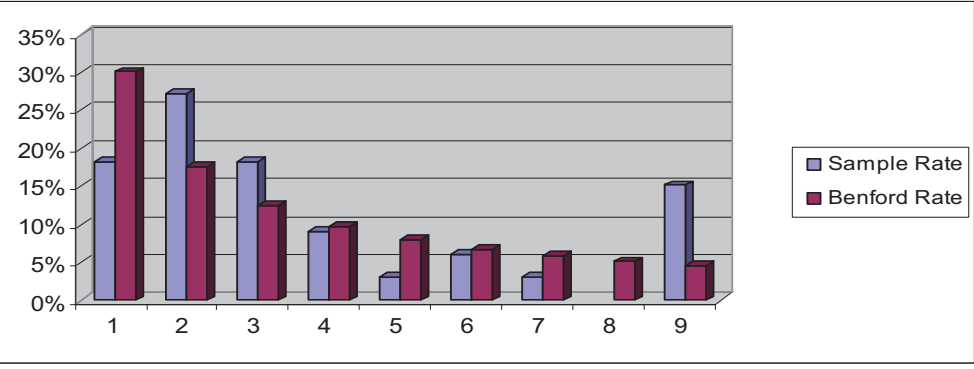


Table 5 Dibër district 2009 Electoral 1BL Result

\begin{tabular}{|l|l|}
\hline Group of parties based on 1BL had an increase in votes & Group of parties based on 1BL had a decrease of votes \\
\hline 2 (AD, LDK, PFA, PLL, POSH, PMDE, PBDNJ, PDS, PS) 9.7\% & 1 (PBKD, PR, LZHK, PDK, PRRL, PGJ, PSV 91) - $11.9 \%$ \\
3 (PAA, ADS, PD, PDI, LSI, G 99) 5.7\% & 4 (PDM e Re, PKONS, LDLNJ) $-0.6 \%$ \\
9 (PBK, BLD, AMIE, PDRESH, PBD) 10.6\% & 5 (PRDSH) -4.9\% \\
& 6 (PSD, PLIDR) $-0.6 \%$ \\
& 7 (PBK) $-2.8 \%$ \\
8 (empty set of data) $-5.1 \%$ \\
\hline
\end{tabular}

In the Dibër district, the groups of parties of the normal distribution that have more votes within the Benford's distribution are 2, 3, 9 (the highest increase of counted votes in this district $+10.6 \%$ ). In the left table column, 13 parties of the Changing Alliance Coalition make $65 \%$ of the total number of parties that have experienced an increase in counted votes. This coalition based on 1BL, has performed the most manipulation in its interest. The other parties that have an increase are from the Socialist Movement for Integration Coalition, LSI and PMDE.

The group of parties which have less than they should have as per $1 \mathrm{BL}$ distribution is group 1 (with $-11.9 \%$ ) part of which are PGJ, PSV 91 (part of the same coalition of the largest parties with vote increase, the Socialist Movement for Integration Alliance), LZHK, PDK, PRRL (Freedom Pole Alliance) and PBKD, PR, (Changing Alliance Coalition). The parties of the Union for Change don't appear in this group except PSD (party of group 6) with not significant change in vote count $(-0.6 \%)$.

Different from other groups, 5 and 7 are formed by only one party. As per 1BL in this district, PRDSH lost $4.9 \%$ of its votes and PBK lost $2.8 \%$ of it votes. If these parties hadn't lost this percentage of votes in Dibër district, they could have had the possibility, based on the Albanian electoral code (Electoral Code of Albania, 2008) to win parliamentary mandate (1-2 mandates). However, it didn't happen; the real counted votes were low, respectively $0.14 \%$ and $0.01 \%$ (table 28). There is also a very suspicious group of $-5.1 \%$ (group 8), an empty data set of counted vote which is translated in a full fraud of votes. It can not be said anything more in this case because it is an empty set and it is impossible to suppose which were the parties that these votes have been shifted. As a conclusion, the distribution of first digits of Benford's Law doesn't correspond to the normal distribution of the Dibër real election data. Smaller parties of the Changing Alliance Coalition were the most beneficiary of the counted votes increase. Also PD, LSI and PS were part of the "has done manipulation" groups. In the right table column presenting parties with a decrease percentage of counted votes is worth to mention that in this case the Freedom Pole Alliance Parties are the most damaged ones.

\subsection{Durrës district 2009 Electoral Results 1BL Analyze}

Table 6 Durrës district 2009 Parliamentary Result

\begin{tabular}{|l|l|l|l|l|}
\hline 1BL & Count & Sample Rate & Benford Rate & Fraud Measure $\Delta \%$ \\
\hline 1 & 7 & $21.2 \%$ & $30.1 \%$ & $-8.9 \%$ \\
\hline 2 & 7 & $21.2 \%$ & $17.6 \%$ & $3.6 \%$ \\
\hline 3 & 8 & $24.2 \%$ & $12.5 \%$ & $11.7 \%$ \\
\hline 4 & 2 & $6.1 \%$ & $9.7 \%$ & $-3.6 \%$ \\
\hline 5 & 3 & $9.1 \%$ & $7.9 \%$ & $1.2 \%$ \\
\hline 6 & 2 & $6.1 \%$ & $6.7 \%$ & $-0.6 \%$ \\
\hline 7 & 1 & $3.0 \%$ & $5.8 \%$ & $-2.8 \%$ \\
\hline 8 & - & - & $5.1 \%$ & $-5.1 \%$ \\
\hline 9 & 3 & $9.1 \%$ & $4.6 \%$ & $4.5 \%$ \\
\hline
\end{tabular}

Graph 3 Durrës district 2009 Parliamentary Result

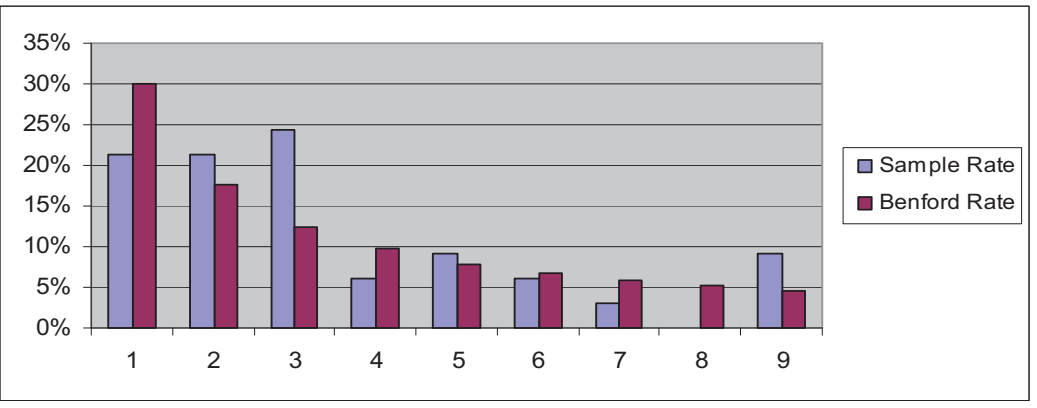


Table 7 Durrës 2009 Electoral 1BL Result

\begin{tabular}{|l|l|}
\hline Group of parties based on 1BL had an increase in votes & Group of parties based on 1BL had a decrease of votes \\
\hline 2 (BLD, AMIE, PDRESH, PR, PRDSH, PKONS, PMDE) 3.6\% & 1 ( PDM e Re, POSH, PDI, PDK, PRRL, LDLNJ, PTR, PSD) $-8.9 \%$ \\
3 (AD, PBK, PBKD, PFA, PBD, PGJ, PBDNJ) 11.7\% & 4 (PAA, PS) $-3.6 \%$ \\
5 (LZHK, PSV 91, PDS) 1.2\% & 6 (PD, PLL) $-0.6 \%$ \\
9 (LDK, ADS, LSI) 4.5\% & 7 (G 99) - $2.8 \%$ \\
& 8 (empty set of data) $-5.1 \%$ \\
\hline
\end{tabular}

As it can be noticed from graph 3 , there is no correlation between the two combined forms of distributions columns as also Table 6 confirms it. In Durrës district, it is worth mentioning that the two largest parties PD and PS result with a decrease of counted votes. PD is in group with first digit vote number starting with 6 with a smaller party of its coalition with a decrease of $0.6 \%$, not as a significant loss as the group in which is PS with $-3.6 \%$ (group 4 ) is present. Instead the third major party, LSI, belongs to the group 9 as well as other parties of the Alliance of Change with an increase of $+4.5 \%$. Socialist Movement for Integration coalition has also smaller parties in group 2, 3 and 5 which probably have benefited from vote counting. However, $10 / 20=>50 \%$ of the parties which based on $1 \mathrm{BL}$ have obtained an increase in votes from manipulation are part of the Changing Alliance Coalition. There are also present small parties of the Freedom Pole Alliance with vote gaining, but the most probable to have done manipulation (increase of votes) are firstly the members of the Changing Alliance Coalition and secondly LSI. The Union of Change Coalition, from the data seems to have suffered more from the decreasing counted votes since parties of this coalition appear with loss votes, as also its main party. A very important data to analyze is the $-2.8 \%$ of vote loss of the $G 99$ party (group 7 ). This increase in vote percentage could have given this party 1 mandate in Durrës district; instead this party got no mandate as the real data percentage was only $0.49 \%$. Interesting to be mentioned in this district is the first digit 8 group with a $-5 \%$ in votes. As in some of the other district as well, also this one is an empty data set suffering a total manipulation and thus it is impossible to suppose to which party this votes based on $1 \mathrm{BL}$ have been shifted.

It can be concluded that the distribution of first digits of Benford's Law doesn't correspond to the normal distribution of the Durrës real election data. The Changing Alliance Coalition and LSI seem the most probable candidates to have benefited or done manipulation in contrary to PS and its coalition members.

\subsection{Elbasan district 2009 Electoral Results 1BL Analyze}

Table 8 Elbasan district 2009 Parliamentary Result

\begin{tabular}{|l|l|l|l|l|}
\hline 1BL & Count & Sample Rate & Benford Rate & Fraud Measure $\Delta \%$ \\
\hline 1 & 6 & $18.2 \%$ & $30.1 \%$ & $-11.9 \%$ \\
\hline 2 & 8 & $24.2 \%$ & $17.6 \%$ & $6.6 \%$ \\
\hline 3 & 4 & $12.1 \%$ & $12.5 \%$ & $-0.4 \%$ \\
\hline 4 & 4 & $12.1 \%$ & $9.7 \%$ & $2.4 \%$ \\
\hline 5 & 3 & $9.1 \%$ & $7.9 \%$ & $1.2 \%$ \\
\hline 6 & 3 & $9.1 \%$ & $6.7 \%$ & $2.4 \%$ \\
\hline 7 & 4 & $12.1 \%$ & $5.8 \%$ & $6.3 \%$ \\
\hline 8 & - & - & $5.1 \%$ & $-5.1 \%$ \\
\hline 9 & 1 & $3.0 \%$ & $4.6 \%$ & $-1.5 \%$ \\
\hline
\end{tabular}

Graph 4 Elbasan district 2009 Parliamentary Result

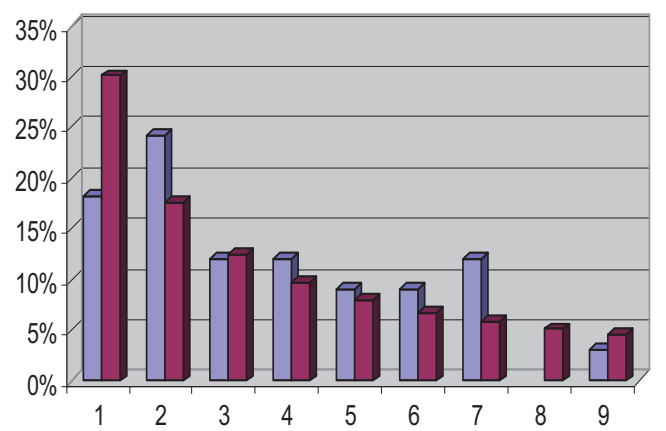


Table 9 Elbasan 2009 Electoral 1BL Result

\begin{tabular}{|l|l|}
\hline Group of parties based on 1BL had an increase in votes & Group of parties based on 1BL had a decrease of votes \\
\hline 2 (PAA, ADS, PDRESH, PFA, PDK, PRDSH, PSD, PLIDR) $6.6 \%$ & 1 ( BLD, PBK, PBKD, PDM e Re, LDLNJ, PBDNJ, G 99) - \\
4 (PRRL, PGJ, PMDE, PSV 91) 2.4\% & $11.9 \%$ \\
5 (AD, PD, PBD) 1.2\% & 8 (empty set of data) $-5.1 \%$ \\
6 (PS) 2.4\% & 9 (PDI) -1.5\% \\
7 (LDK, PLL, POSH, LSI) $6.3 \%$ & \\
\hline
\end{tabular}

In Elbasan district the counted votes as per 1BL were manipulated as well since the Benford distributions curve doesn't match the real data one (graph 4). The only point where they have an almost perfect match is $1 \mathrm{BL} 12 \%$ (group 3, PR, LZHK, PKONS and PTR). It can be said that these parties did not commit or suffer manipulation. A total shift of votes instead has happened in group $8(-5.1 \%)$ being disrupted and distributed to other parties as per 1BL. As per the presented situation, there are chances that the Changing Alliance Coalition (PAA, ADS, PDRESH, PFA, AD, PD, LDK, PLL, POSH) is the largest beneficiary of the votes shift since $45 \%$ of the parties with increase of votes belong to it, group 2 with an increase of $+6.6 \%(4 / 8)$ and group 7 with $+6.3 \%(3 / 4)$.

LSI group is the second most present with an increase percentage of votes present in group 4 with $+2.4 \%$ increase (PG, PMDE, PSV 91) and its main party LSI present in the group 7 of an $+6.3 \%$ increase together with small parties of the Changing Alliance Coalition. There are also parties from the Freedom Pole coalition and Independent parties experiencing an increase: PLIDR, PDK, PRDSH, and PBD. The clearest fraud in this district is the one of the PS party (group 6 , component only by this party) of $+2.4 \%$ increase. This result probably gave this party one more parliamentary mandate which as per 1BL could not have been happened. Instead the $\mathrm{G} 99$ and PBDNJ, parties of Union of Change coalition, had loss percentage of votes (part of group 1, of -11.9\%). The group of 1 also contains 4 small parties of the Changing Alliance Coalition (BLD, PBK, PBKD, PDM e Re), and LDLNJ. Moreover another party with a decrease of votes is PDI party with a decrease of $1.5 \%$. Such a result might have negatively affected this party which had the possibility for a gaining potential candidate in this district if all the other data had been the same.

Although group 3 distribution match to the $1 \mathrm{BL}$, it can be said that the distribution of first digits of Benford's Law doesn't correspond to the normal distribution of the Elbasan real election data. All the three main parties, PS, PD, and LSI had an increase of votes. The most probable situation is that from these three main parties, PS was the most advantageous in vote increasing percentage. The empty set of $-5.1 \%$ for the 8 group of first digit number of votes which most probably have been shifted to the other parties might also had a considerable effect on the district mandate results.

\section{6 Fier district 2009 Electoral Results 1BL Analyze}

Table 10 Fier district 2009 Parliamentary Result

\begin{tabular}{|l|l|l|l|l|}
\hline 1BL & Count & Sample Rate & Benford Rate & Fraud Measure $\Delta \%$ \\
\hline $\mathbf{1}$ & 11 & $33.33 \%$ & $30.1 \%$ & $3.23 \%$ \\
\hline $\mathbf{2}$ & 6 & $18.18 \%$ & $17.6 \%$ & $0.57 \%$ \\
\hline $\mathbf{3}$ & 6 & $18.18 \%$ & $12.5 \%$ & $5.69 \%$ \\
\hline $\mathbf{4}$ & 2 & $6.06 \%$ & $9.7 \%$ & $-3.63 \%$ \\
\hline $\mathbf{6}$ & 3 & $9.09 \%$ & $7.9 \%$ & $1.17 \%$ \\
\hline $\mathbf{7}$ & 2 & $6.06 \%$ & $6.7 \%$ & $-0.63 \%$ \\
\hline $\mathbf{8}$ & - & - & $5.8 \%$ & $-5.80 \%$ \\
\hline $\mathbf{9}$ & 2 & $6.06 \%$ & $5.1 \%$ & $0.95 \%$ \\
\hline
\end{tabular}

Graph 5 Fier district 2009 Parliamentary Result

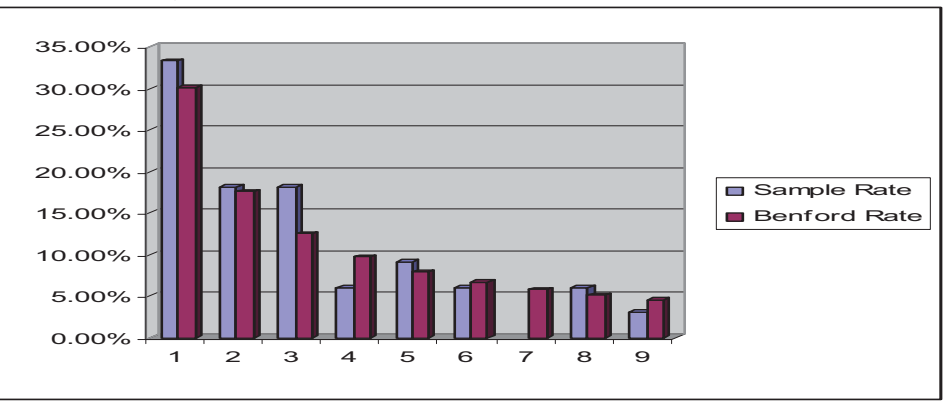


Table 11 Fier 2009 Electoral 1BL Result

\begin{tabular}{|l|l|}
\hline Group of parties based on 1BL had an increase in votes & Group of parties based on 1BL had an decrease of vote \\
\hline 1 ( PAA, ADS, PBKD, PDRESH, PDM e Re, PRDSH, PKONS, & 4 ( AD, PDI) -3.63\% \\
LDLNJ, LSI, PTR, PDS, G 99) 3.23\% & 6 (PBDNJ, PBK, PDK) $-0.63 \%$ \\
2 ( AMIE, PLL, LZHK, PRRL, PMDE, PLIDR) $0.57 \%$ & 7 (empty set of data) $-5.8 \%$ \\
3 (PFA, PR, PBD, PGJ, PSV 91, PSD) 5.69\% & 9 (POSH) - $1.55 \%$ \\
5 (LDK, PD, PBDNJ) $1.17 \%$ & \\
8 (BLD, PS) $0.95 \%$ & \\
\hline
\end{tabular}

In Fier district, as it can be seen from the table 10 and graph 5, different from the other distribution analyzed above and the ones below, the margin of electoral fraud based on the $1 \mathrm{BL}$, is the smallest of the 12 Albanian Electoral District. Fier is the second largest district in Albania, following Tirana, with 16/140 parliamentary deputy mandates.

It is interesting to mention that the two main Political Parties, PD and PS, as shown in table 6, result to be in group 5 and 8 , with only a small percentage increase in votes. As per the same analysis based on the $1 \mathrm{BL}$, if these two parties have done manipulation, it probably is done through their smaller coalition's members to increase the coalition number of votes in total and enforce the coalition position against the Union for Change Coalition. LSI and its coalition parties are also important to be mentioned here because also these parties are part of the ones that had an increase in votes (LDLNJ, LSI, PTR, PGJ, PSV 91, PMDE, PBDNJ), but also they do not have an increase that could bring a negative impact to the other two main Parties, PD and PS. The highest group with vote gaining in this district as per $1 \mathrm{BL}$ is the group 3 with $+5.69 \%$ composed from parties of all 2009 coalitions. It looks like all the three of them and their smaller parties in coalition are balanced with each-other fraud of votes, it's like a balance sheet of losing-winning of counted votes.

However, suspicious and hard to be explained remains group 7 with $-5.8 \%$, since it is an empty data set of parties, a total shift of votes towards other parties probably towards parties who have resulted with vote increase.

In this case it can be said that except group 7 and 3 and 4 , the other normal distribution of votes are almost equal to the $1 \mathrm{BL}$, which means that in the Fier district distribution of first digits of Benford's Law correspond partially to the normal distribution that its real election data. In this case "partially" means that "most of the differences of margin between the two statistical distributions are almost at a low level, but not totally match". Anyway the PD party and its coalition, the Changing Alliance Coalition, although not in a high percentage, remains the probable most beneficiary of the increasing of counted vote, although with not such an impact differences from the other parties and coalitions, such as the Socialist Movement for Integration, The Freedom Pole and Union of Change.

\subsection{Gjirokastra district 2009 Electoral Results 1BL Analyze}

Table 12 Gjirokastra district 2009 Parliamentary Result

\begin{tabular}{|l|l|l|l|l|}
\hline 1BL & Count & Sample Rate & Benford Rate & Fraud Measure $\Delta \%$ \\
\hline 1 & 12 & $36.4 \%$ & $30.1 \%$ & $6.3 \%$ \\
\hline 2 & 4 & $12.1 \%$ & $17.6 \%$ & $-5.5 \%$ \\
\hline 3 & 4 & $12.1 \%$ & $12.5 \%$ & $-0.4 \%$ \\
\hline 4 & 1 & $3.0 \%$ & $9.7 \%$ & $-6.7 \%$ \\
\hline 5 & 2 & $6.1 \%$ & $7.9 \%$ & $-1.9 \%$ \\
\hline 6 & 4 & $12.1 \%$ & $6.7 \%$ & $5.4 \%$ \\
\hline 7 & 2 & $6.1 \%$ & $5.8 \%$ & $0.3 \%$ \\
\hline 8 & 1 & $3.0 \%$ & $5.1 \%$ & $-2.1 \%$ \\
\hline 9 & 3 & $9.1 \%$ & $4.6 \%$ & $4.5 \%$ \\
\hline
\end{tabular}

Graph 6 Gjirokastra district 2009 Parliamentary Result

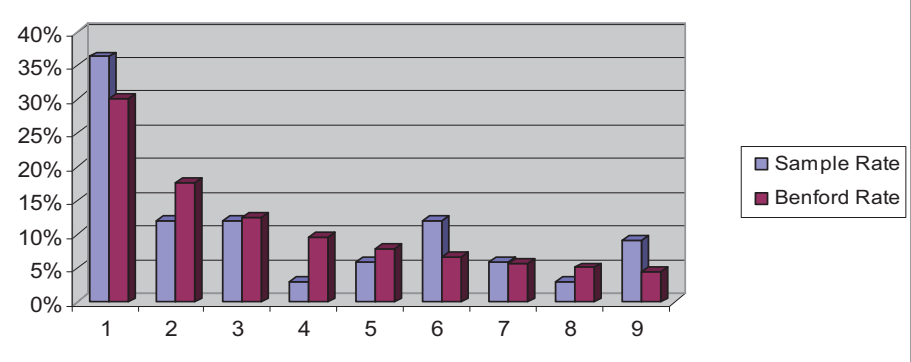


Table 13 Gjirokastra 2009 Electoral 1BL Result

\begin{tabular}{|l|l|}
\hline Group of parties based on 1BL had an increase in votes & Group of parties based on 1BL had a decrease of votes \\
\hline 1 ( PAA, PBKD, PD, PFA, LZHK, PBD, PDK, PKONS, LDLNJ, & 2 ( AD, ADS, PBDNJ, PS) -5\% \\
LSI, PGJ, PMDE, PTR) 6\% & 4 (BLD) -7\% \\
6 (AMIE, PRRL, G 99, PLIDR) $5 \%$ & 5 (PBK, PSV 91) - $2 \%$ \\
9 (POSH, PR, PSD) 5\% & 8 (PDS) -2\% \\
\hline
\end{tabular}

In Gjirokastra district, based on graph 6 and table 12, it can be seen that parties of group 3 (LDK, PDM e Re, PLL, PDI) and 7 (PDRESH, PRDSH, PDS) have an almost perfect match to the 1BL. It can be said here that in groups 3 and 7 were not committed or suffered electoral fraud. The distribution of increased votes in this district (table 13) is more balanced between the parties of the Coalitions (except for the Union of Change with only two parties).

LSI and PD are both in group 1. The Changing Alliance Coalition remains the most probable coalition to have the major increase of its percentage of votes since its parties are distributed in all of the three beneficiary groups.

The most loss of percentage votes in this district pertains to the Union of Change Coalition. Its parties are 4/8 of those experiencing a decrease in votes, apart of which is also the PS party belonging to group 2 with $-5 \%$ in counted votes.

From the analysis of this district, it can be concluded that based on the $1 \mathrm{BL}$, the Changing Alliance Coalition and the LSI Coalition had the most increase in vote percentage. The Freedom of Pole also is part of the vote increase, but taking into consideration that these parties coalition are not too powerful in the electoral game of Albania, they have less chance to be equal beneficiary as the two other mentioned above. On the other hand, the major decrease of vote numbers was suffered from the Union of Change. It is obvious that also PDS experienced $-2 \%$ vote percentage shift as per 1BL. This percentage could have helped this party to win a parliamentary mandate (instead they got no mandate because they had only $1.84 \%$ of votes in the real data). It can be said that most of the statistical vote counts distribution of first digits of Benford's Law doesn't correspond to the normal distribution that is in the Gjirokastra real election data which partially matches the Benford's Law.

Also important is to mention, that in the Gjirokastra district there are no groups with empty data sets and is the only district in Albania with all groups being present. Despite oscillations of the sample rate and of the Benford rate, the non existence of an empty set supports idea that the vote results in these districts are balanced and the shift of votes is more easily noticed.

\subsection{Korca District 2009 Electoral Results 1BL Analyze}

Table 14 Korca's City 2009 Parliamentary Result

\begin{tabular}{|l|l|l|l|l|}
\hline 1BL & Count & Sample Rate & Benford Rate & Fraud Measure $\Delta \%$ \\
\hline $\mathbf{1}$ & 2 & $6.1 \%$ & $30.1 \%$ & $-24.0 \%$ \\
\hline $\mathbf{2}$ & 11 & $33.3 \%$ & $17.6 \%$ & $15.7 \%$ \\
\hline $\mathbf{3}$ & 5 & $15.2 \%$ & $12.5 \%$ & $2.7 \%$ \\
\hline $\mathbf{4}$ & 4 & $12.1 \%$ & $9.7 \%$ & $2.4 \%$ \\
\hline $\mathbf{5}$ & 3 & $9.1 \%$ & $7.9 \%$ & $1.2 \%$ \\
\hline $\mathbf{6}$ & 5 & $15.2 \%$ & $6.7 \%$ & $8.5 \%$ \\
\hline $\mathbf{7}$ & 2 & $6.1 \%$ & $5.8 \%$ & $0.3 \%$ \\
\hline $\mathbf{8}$ & - & - & $5.1 \%$ & $-5.1 \%$ \\
\hline $\mathbf{9}$ & 1 & $3.0 \%$ & $4.6 \%$ & $-1.5 \%$ \\
\hline
\end{tabular}

Graph 7 Korca City 2009 Parliamentary Result

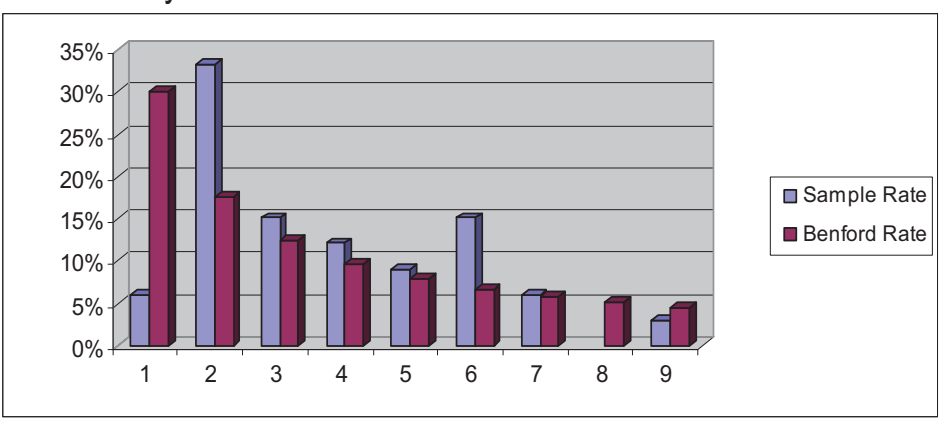


Table 15 Korça 2009 Electoral 1BL Result

\begin{tabular}{|l|l|}
\hline Group of parties based on 1BL had an increase in votes & Group of parties based on 1BL had a decrease of votes \\
\hline 2 ( AD, LDK, PDRESH, PDM e Re, PFA, PR, PBD, PRRL, PSV & 1 (PBKD, PRDSH, PSD) -24\% \\
91, PTR, PBDNJ) 15.7\% & 8 (empty set of data) $-5.1 \%$ \\
3 ( PLL, POSH, LZHK, PDK, PGJ) 2.7\% & 9 (G 99) -1.5\% \\
4 (PBK, PDI, LSI, PMDE) 2.4\% & \\
5 (PD, PS, PLIDR) 1.2\% & \\
6 (PAA, AMIE, ADS, LDLNJ, PDS) $8.5 \%$ & \\
\hline
\end{tabular}

In Korca district counted vote present in the group 7 has an almost perfect match to the $1 \mathrm{BL}$ of $6 \%$, but on the other hand this district has the highest margin of differences between the highest increase of $15.7 \%$, and the highest decrease in votes of $24 \%$. This means that manipulation could be easily have been done in this district rather than in the other 11 electoral district of Albania. In group 2 of the +15.7 percent the Changing Alliance Coalition parties are 6/11 of the present parties in this group, meaning the party of this coalition are highly probable to be the most beneficiary of the increased votes. This argument is supported also by the fact that the Changing Alliance Coalition Parties make 50\% (AD, LDK, PDRESH, PDM e Re, PFA, PR, PLL, POSH, PBK, PDI, PD, PAA, AMIE, ADS) of the total beneficiary parties in the left column of table 15, and in the decreased column this coalition is present with only one party (PBKD).

Highly suspicious is the group 1. It is composed by only three parties (PBKD, PRDSH, PSD) which has the highest vote fraud of $-24 \%$. This means that if this percentage was not incurred from these parties votes, very much probably all three of them could have the possibility to be a potentially winner of a minimum one mandate for the 2009 legislature. The G 99 party (of the Union of Change Coalition) has $-1.5 \%$, meaning that this party have lost the probability to win an electoral mandate. Upon this reasoning, I can suppose that the Union of Change Coalition (mostly present in the parties based on $1 \mathrm{BL}$ had a decrease of votes) is the coalition that lost the most percentage of votes. This argument is also supported by the fact that the PS is present in group of 5 of only $1.2 \%$ increase of vote, not to significant. In this matter of facts, for group 8 (an empty data set) I can only suppose that the highest probability is that votes from the Union of Change formed this group of first digit data. It can be said that the statistical counted votes distribution of first digits of Benford's Law doesn't correspond to the normal distribution of the Korca real election data. The margin of differences between normal and 1BL distribution varies a lot from one group of parties to another. The most beneficiary parties in count votes based on $1 \mathrm{BL}$ probable are the Changing Alliance Coalition, then the Socialist Movement Coalition. Instead the probability that the Union of Change had vote loss is high.

\subsection{Kukës District 2009 Electoral Results 1BL Analyze}

Table 18 Kukës's District 2009 Parliamentary Result

\begin{tabular}{|l|l|l|l|l|}
\hline $1 \mathrm{BL}$ & Count & Sample Rate & Benford Rate & Fraud Measure $\Delta \%$ \\
\hline $\mathbf{1}$ & 12 & $36.4 \%$ & $30.1 \%$ & $6.3 \%$ \\
\hline $\mathbf{2}$ & 6 & $18.2 \%$ & $17.6 \%$ & $0.6 \%$ \\
\hline $\mathbf{3}$ & $\mathbf{5}$ & $15.2 \%$ & $12.5 \%$ & $2.7 \%$ \\
\hline $\mathbf{4}$ & 6 & $18.2 \%$ & $9.7 \%$ & $8.5 \%$ \\
\hline $\mathbf{5}$ & 1 & $3.0 \%$ & $7.9 \%$ & $-4.9 \%$ \\
\hline $\mathbf{6}$ & - & - & $6.7 \%$ & $-6.7 \%$ \\
\hline $\mathbf{7}$ & 1 & $3.0 \%$ & $5.8 \%$ & $-2.8 \%$ \\
\hline $\mathbf{8}$ & 2 & $6.1 \%$ & $5.1 \%$ & $0.9 \%$ \\
\hline $\mathbf{9}$ & - & - & $4.6 \%$ & $-4.6 \%$ \\
\hline
\end{tabular}

Graph 8 Kukës District 2009 Parliamentary Result

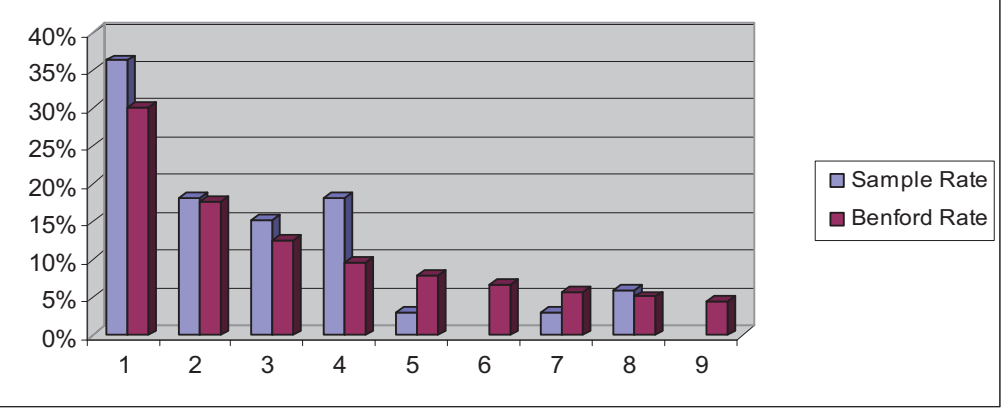


Table 19 Kukës 2009 Electoral 1BL Results

\begin{tabular}{|l|l|}
\hline Group of parties based on 1BL had an increase in votes & Group of parties based on 1BL had a decrease of votes \\
\hline 1 ( LDK, PAA, PDRESH, POSH, PDI, PR, LZHK, PRDSH, & 5 ( PLL) -4.9\% \\
PKONS, LSI, PBDNJ, G 99) $6.3 \%$ & 6 (empty set of data) $-6.7 \%$ \\
2 ( BLD, PD, PBD, PGJ, PDS, PLIDR) $0.6 \%$ & 7 (PBKD) $-2.8 \%$ \\
3 (AD, AMIE, PDM e Re, LDLNJ, PTR) 2.7\% & 9 (empty set of data) $-4.6 \%$ \\
4 (ADS, PBK, PDK, PRRL, PSV 91, PSD) $8.5 \%$ & \\
8 (PFA, PS) $0.9 \%$ & \\
\hline
\end{tabular}

Kukës is not different from the other districts as the results are suspicious based on 1BL. Parties from all coalitions have made fraud since the most large data set of decreased percentage in votes are empty, group $6(-6.7 \%)$ and $9(-4.6 \%)$. The remaining two groups that have data in them are from the Changing Alliance, PLL (-4.9\% of it votes) and PBKD ($2.8 \%$ of its votes). It is clear that if these parties haven't lost votes, could have been strong candidates for wining minimum one mandate for the 2009 parliamentary election.

Groups 2 and 8 have the lowest difference between the real distribution and Benfords' one at the $0.6 \%$ and $0.9 \%$ (part of this group is also PS) meaning that there has been not too much fraud from the parties in these groups because they have only $0.6 \%$ of votes over the $1 \mathrm{BL}$ distribution. Groups 1,3 and 4 have more votes as per the $1 \mathrm{BL}$ data set, meaning that presumably they have done vote manipulation. $44 \%$ of the present parties in the column of increased vote percentage are from the Changing Alliance Coalition (LDK, PAA, PDRESH, POSH, PDI, PR, BLD, PD, AD, AMIE, PDM e $\mathrm{Re}, \mathrm{ADS}, \mathrm{PBK}$ and PFA). These parties have the most probability to have done manipulation, although the main party of this coalition is in group 2 with an insignificant increase in votes (+0.6\%) compared to $\mathrm{LSI}$, which is in the $+6.3 \%$ increase of votes. Also PS is in group 8, witch can be also considered as insignificant fraud, but parties of Union for Change Coalition PBDNJ, G 99, PDS, PSD, belong to the groups that had a significant increase in votes (1 and 4).

The above analysis takes into the conclusion that the two main parties of Albania PD and PS have not done vote manipulation directly, but in an indirect way, of making manipulation in increasing the percentage of their coalition's small parties, so on to increase the coalition percentage in their benefit. In contrary as mentioned above it can not be said the same for the third main party of Albania LSI, because this party and its coalition parties PGJ, LDLNJ, PTR, PSV 91, belong to groups that had a considerable increase in votes.

Important as the one mentioned above are the Freedom of Pole Coalition parties (LZHK, PRDSH, PKONS, PBD, PDK, PRRL), which also have the probability to have done manipulation of votes. Although these are smaller and weaker parties compared to PS, PD and LSI and their respective coalitions (smaller parties are helped from the main parties).

As in Korca, for Kukës district it can be seen the margin of differences between normal and 1BL distribution varies a lot from one group to another, as for this, it can be said that the statistical vote counts distribution of first digits of Benford's Law doesn't correspond to the normal distribution that is in the Korca real election data, as the presence of the Changing Alliance Coalition is $14 / 32,44 \%$ of the total number of parties that probable had an increase. Probable to have done manipulation is also the Socialist movement for Integration Coalition and less party from the Union for Change.

\subsection{Lezha District 2009 Electoral Results 1BL Analyze}

Table 20 Lezha's District 2009 Parliamentary Result

\begin{tabular}{|l|l|l|l|l|}
\hline $\mathbf{1 B L}$ & Count & Sample Rate & Benford Rate & Fraud Measure $\mathbf{\Delta} \%$ \\
\hline $\mathbf{1}$ & 15 & $45.5 \%$ & $30.1 \%$ & $15.4 \%$ \\
\hline $\mathbf{2}$ & 7 & $21.2 \%$ & $17.6 \%$ & $3.6 \%$ \\
\hline $\mathbf{3}$ & 3 & $9.1 \%$ & $12.5 \%$ & $-3.4 \%$ \\
\hline $\mathbf{4}$ & 3 & $9.1 \%$ & $9.7 \%$ & $-0.6 \%$ \\
\hline $\mathbf{5}$ & - & - & $7.9 \%$ & $-7.9 \%$ \\
\hline $\mathbf{6}$ & 1 & $3.0 \%$ & $6.7 \%$ & $-3.7 \%$ \\
\hline $\mathbf{7}$ & 2 & $6.1 \%$ & $5.8 \%$ & $0.3 \%$ \\
\hline $\mathbf{8}$ & 1 & $3.0 \%$ & $5.1 \%$ & $-2.1 \%$ \\
\hline $\mathbf{9}$ & 1 & $3.0 \%$ & $4.6 \%$ & $-1.5 \%$ \\
\hline
\end{tabular}


Graph 9 Lezha's District 2009 Parliamentary Result

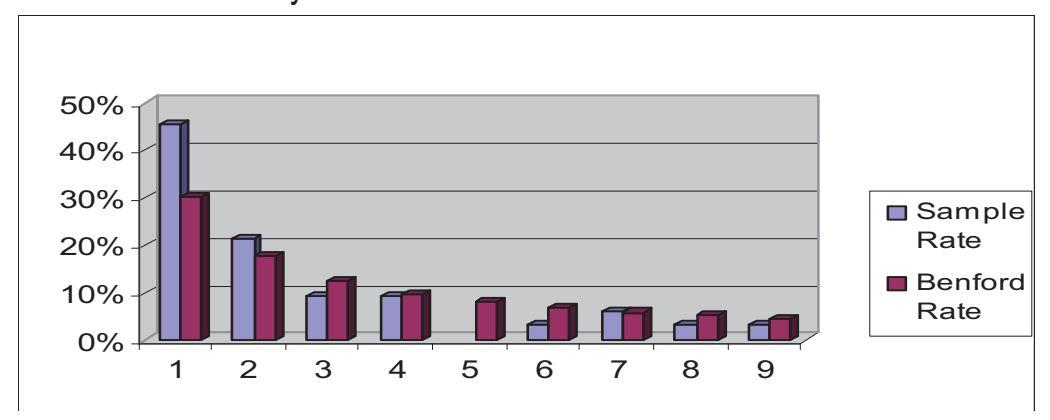

Table 21 Lezha 2009 Electoral 1BL Result

\begin{tabular}{|l|l|}
\hline Group of parties based on 1BL had an increase in votes & Group of parties based on 1BL had a decrease of votes \\
\hline 1 ( LDK, PAA, AMIE, ADS, PDRESH, PFA, PLL, POSH, PR, & 3 ( AD, PD, G 99) -3\% \\
LZHK, PDK, PGJ, PMDE, PSV 91, PTR, PLIDR) 15\% & 4 (BLD, PKONS, PRRL) -1\% \\
2 ( PDM e Re, PDI, LSI, PBDNJ, PDS, PSD, PS) 4\% & 5 (empty set of data) -8\% \\
& 6 (PBKD) -4\% \\
& 8 (PBK) - $2 \%$ \\
& 9 (PBD) - $2 \%$ \\
\hline
\end{tabular}

Lezha district is also another example of none uniformly of $1 \mathrm{BL}$ vote distribution, although the margins of oscillation are not to large, as it can be seen from graph 9, the real data set distribution follows a softer trend line, as the 1BL, although column one and five has no match at all between the two distributions.

More specifically it can be analyzed the data from table 21 , where it can be seen that the 7 first digit groups (PRDSH, LDLNJ) has a match between the normal and 1BL statistical distribution at $6 \%$. But contrary to this, the other first digit groups does not match, which means that based on 1BL there have been fraud. The highest first digit parties groups of normal distribution having more then $1 \mathrm{BL}$ is $1(+15 \%) 9 / 16 \Rightarrow 56.2 \%$ of which are from the Changing Alliance Coalition (LDK, PAA, AMIE, ADS, PDRESH, PFA, PLL, POSH, PR) and the rest from the LSI Coalition (PGJ, PMDE, PSV 91, PTR,) and an independent party PLIDR, and LZHK, PDK. In group $2(+4 \%)$ there are also 2 more parties of the Changing Alliance Coalition (PDM e Re, PDI), the LSI party and PBDNJ, PDS, PSD, PS (Union of Change Coalition parties).

It is clear that the Changing Alliance Coalition parties are present in the most increased percentage of votes groups, followed from the Socialist Movement for Integration Coalition. It is interesting in this district as in the Kukës analyzed above that the main parties of the Coalitions, PS and LSI belong both to the low increased percentage of the counted votes. Instead the other main party, PD at contrary of its coalition smaller parties is in group 3 that had a lost of $3 \%$ in votes. Group 8 have had a total fraud of votes, which probably have been distributed in the other groups that have more votes than the $1 \mathrm{BL}$.

Based on $1 \mathrm{BL}$ there are three parties PBKD, PBK, PBD as it is clearly shown that they lost votes respectively $4 \%$ the first and $2 \%$ the other two. These parties could have won a parliamentary mandate, and the most probable of them is the PBKD party of the Changing Alliance Coalition.

\subsection{Shkodra District 2009 Electoral Results 1BL Analyze}

Table 22 Shkodra's District 2009 Parliamentary Result

\begin{tabular}{|l|l|l|l|l|}
\hline $\mathbf{1 B L}$ & Count & Sample Rate & Benford Rate & Fraud Measure $\mathbf{\Delta} \%$ \\
\hline $\mathbf{1}$ & $\mathbf{5}$ & $15.2 \%$ & $30.1 \%$ & $-15.0 \%$ \\
\hline $\mathbf{2}$ & 12 & $36.4 \%$ & $17.6 \%$ & $18.8 \%$ \\
\hline $\mathbf{3}$ & 4 & $12.1 \%$ & $12.5 \%$ & $-0.4 \%$ \\
\hline $\mathbf{4}$ & 4 & $12.1 \%$ & $9.7 \%$ & $2.4 \%$ \\
\hline $\mathbf{5}$ & 4 & $12.1 \%$ & $7.9 \%$ & $4.2 \%$ \\
\hline $\mathbf{6}$ & 4 & $12.1 \%$ & $6.7 \%$ & $5.4 \%$ \\
\hline $\mathbf{7}$ & - & - & $5.8 \%$ & $-5.8 \%$ \\
\hline $\mathbf{8}$ & - & - & $5.1 \%$ & $-5.1 \%$ \\
\hline $\mathbf{9}$ & - & - & $4.6 \%$ & $-4.6 \%$ \\
\hline
\end{tabular}


Graph 10 Shkodra's District 2009 Parliamentary Result

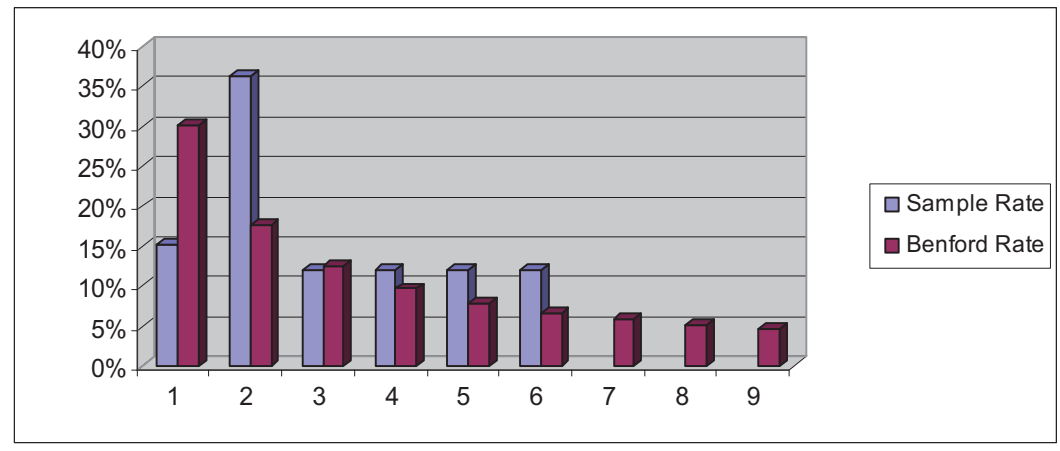

Table 23 Shkodra district 2009 Electoral 1BL Result

\begin{tabular}{|l|l|}
\hline Group of parties based on 1BL had an increase in votes & Group of parties based on 1BL had a decrease of votes \\
\hline 2 ( LDK, PAA, AMIE, PBKD, PLL, POSH, PR, PRRL, LSI, PMDE, & 1 ( BLD, PDRESH, PFA, PGJ, PTR, PBDNJ) - $15 \%$ \\
PDS, PSD) 18.8\% & 7 (empty set of data) $-5.8 \%$ \\
4 ( LZHK, PRDSH, PSV 91, PLIDR) 2.4\% & 8 (empty set of data) $-5.1 \%$ \\
5 (PD, PDI, PBD, G 99) 4.2\% & 9 (empty set of data) $-4.6 \%$ \\
6 (PBK, PDM e Re, PKONS, LDLNJ) $5.4 \%$ & \\
\hline
\end{tabular}

Shkodra district is among the 12 districts the second one to have the highest oscillation between the two distributions. As it can be seen from graph 10, there are 7, 8, 9 first digit votes number groups that have missing votes (empty data sets of votes), meaning they suffered a full fraud of votes.

In this group of shifted votes, I can also put the 1 digit group of parties because it has a great missing of votes with $-15 \%$. These votes, probably, have been distributed to the 2 group (showing the highest increase of votes over the $1 \mathrm{BL}$ of $+18.8 \%), 5$, and 6 first digit votes groups. It is noticeable from table 10 , there has been loss of votes from the Socialist Movement for Integration Coalition (PGJ, PTR), the Union for Change (PBDNJ) and Changing Alliance Coalition (BLD, PDRESH, PFA).

Although, the empty data set doesn't at this point allow analyzing in more details the shifted data. All these uncounted votes from the right column are distributed to the parties based on $1 \mathrm{BL}$ had an increase in votes. Group 2 has the largest increase of counted votes, 7/12 parties of this group belong to the Changing Alliance Coalition. Parties of this coalition are present also in group 5 and 6 . In summary, parties of the Changing Alliance Coalition from most of the number of parties belong to the increased groups with increase of counted vote.

Also LSI (PMDE, PSV 91, LDLNJ) and parties of its coalition are present in this group. They take a much smaller part compared to the Changing Alliance Coalition. The smaller portion of the increased votes belong to the Union of Change Coalition can be interpreted as this coalition and the Socialist Movement for Integration Coalition, had a smaller probability compared to the Changing Coalition Party in doing vote count fraud in Shkodra District.

It can be concluded that the statistical vote counts distribution of first digits of Benford's Law doesn't at all correspond to the normal distribution present in the Shkodra real election data results.

\subsection{Vlora District 2009 Electoral Results 1BL Analyze}

Table 24 Vlora District 2009 Parliamentary Result

\begin{tabular}{|l|l|l|l|l|}
\hline $1 \mathrm{BL}$ & Count & Sample Rate & Benford Rate & Fraud Measure $\Delta \%$ \\
\hline 1 & 6 & $18.2 \%$ & $30.1 \%$ & $-11.9 \%$ \\
\hline 2 & 8 & $24.2 \%$ & $17.6 \%$ & $6.6 \%$ \\
\hline 3 & 7 & $21.2 \%$ & $12.5 \%$ & $8.7 \%$ \\
\hline 4 & 3 & $9.1 \%$ & $9.7 \%$ & $-0.6 \%$ \\
\hline 5 & 2 & $6.1 \%$ & $7.9 \%$ & $-1.9 \%$ \\
\hline 6 & 3 & $9.1 \%$ & $6.7 \%$ & $2.4 \%$ \\
\hline 7 & - & - & $5.8 \%$ & $-5.8 \%$ \\
\hline 8 & 1 & $3.0 \%$ & $5.1 \%$ & $-2.1 \%$ \\
\hline 9 & 3 & $9.1 \%$ & $4.6 \%$ & $4.5 \%$ \\
\hline
\end{tabular}


Graph 11 Vlora district 2009 Parliamentary Result

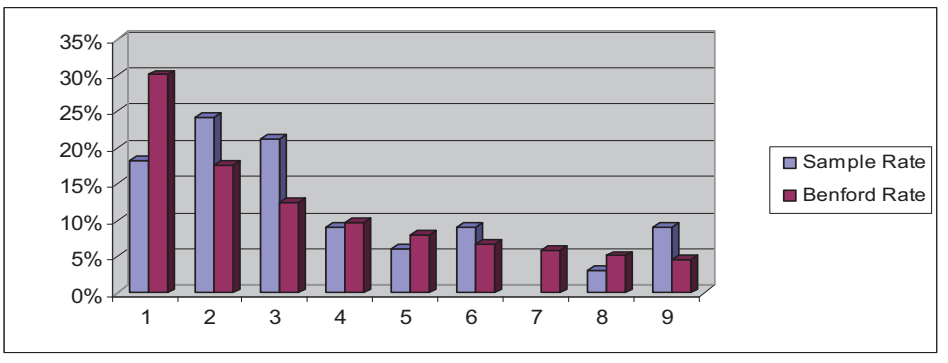

Table 25 Vlora district 2009 Electoral 1BL Results

\begin{tabular}{|l|l|}
\hline Group of parties based on 1BL had an increase in votes & Group of parties based on 1BL had a decrease of votes \\
\hline 2 ( AD, ADS, PFA, PLL, PBD, PRDSH, PGJ, PSD) 6.6\% & 1 ( AMIE, PR, PDK, PKONS, PSV 91, PDS, PLIDR) -11.9\% \\
3 ( LDK, PBKD, PD, LZHK, LDLNJ, LSI, PTR) 8.7\% & 4 (POSH, PDI, PS) $-0.6 \%$ \\
6 (BLD, PDM e Re, PBDNJ) 2.4\% & 5 (PRRL, PMDE) -1.9\% \\
9 (PAA, PDRESH, G 99) 4.5\% & 7 (empty set of data) $-5.8 \%$ \\
& 8 (PBK) -2.1\% \\
\hline
\end{tabular}

Graph 11 and table 24 show that none of the real data distribution matches the 1BL data distribution. Although Vlora district, like a very few districts analyzed in this paper (Fier,) has comparatively lower oscillation margins between these two types of distribution. It is worth mentioning that as per data presented and taken into analysis in this district, PBK party has experienced a $-2.1 \%$ decrease in vote percentage which if not occurred could result in this party to have obtained a mandate in Vlora district. 11 parties of this coalition (Changing Alliance) on the other hand are 11/20 $=55 \%$ of the total present parties result in an increase of votes (table 25). All the other parties that have an increasing percentage of votes are the ones belonging to the Changing Alliance Coalition, in which also its leading political party, PD, is present (group 3) with $+9 \%$ of increase. Also 5 parties of the LSI Coalition had an increased in counted votes, three of which are present in the $+9 \%$ percent of vote (LDLNJ, LSI, PTR). The probability to have had an increase of votes is also present in the LDLNJ and PTR from the Freedom Pole Alliance. They are smaller and less influential parties within the PD and LSI coalitions and their probability to have done manipulation is smaller compared to other the largest parties within the same or other coalitions. The PS as leader of the largest coalition in this district is on the right column of table 25 with decreasing percentage of votes at $-0.6 \%$. The Union of Change Coalition as per $1 \mathrm{BL}$ distribution of votes most probably is part of the group of parties suffering from votes manipulation, although two of its parties in coalition are present to the 2 and 9 groups of respectively with $+6.6 \%$ and $+4.5 \%$ of vote increase. Other parties most likely to have lost votes are AMIE, PR, POSH, PDI (Changing Alliance Coalition), PDK, PKONS, and PRRL (Freedom Pole Coalition) PSV 91, PMDE (Socialist Movement for Integration) and PLIDR (independent party).

As per above, in Vlora district, vote counts is another confirmation of vote fraud. None of the nine first digits normal distribution of vote numbers correlates to $1 \mathrm{BL}$ distribution. Only group 4 real data is almost matching with $1 \mathrm{BL}$ distribution. Most probably, based on $1 \mathrm{BL}$, parties which have made fraud in their interest is firstly the Changing Alliance Coalition and secondly the Socialist Movement for integration Coalition. On the other hand, it is worth mentioning that the 7 first digit number group is an empty data set at a rate of $-5.8 \%$ resulting in these votes to have been shifted to other political parties.

\subsection{Tirana District 2009 Electoral Results 1BL Analyze}

Table 26 Tirana District 2009 Parliamentary Results

\begin{tabular}{|l|l|l|l|l|}
\hline 1BL & Count & Sample Rate & Benford Rate & Fraud Measure $\Delta \%$ \\
\hline $\mathbf{1}$ & 15 & $44.1 \%$ & $30.1 \%$ & $14.0 \%$ \\
\hline $\mathbf{2}$ & 3 & $8.8 \%$ & $17.6 \%$ & $-8.8 \%$ \\
\hline $\mathbf{3}$ & 2 & $5.9 \%$ & $12.5 \%$ & $-6.6 \%$ \\
\hline $\mathbf{4}$ & $\mathbf{5}$ & $11.8 \%$ & $9.7 \%$ & $2.1 \%$ \\
\hline $\mathbf{6}$ & - & - & $7.9 \%$ & $-7.9 \%$ \\
\hline $\mathbf{6}$ & 2 & $5.9 \%$ & $6.7 \%$ & $-0.8 \%$ \\
\hline $\mathbf{8}$ & 1 & $2.9 \%$ & $5.8 \%$ & $-2.9 \%$ \\
\hline $\mathbf{9}$ & 5 & $14.7 \%$ & $5.1 \%$ & $9.6 \%$ \\
\hline
\end{tabular}


Graph 12 Tirana District 2009 Parliamentary Results

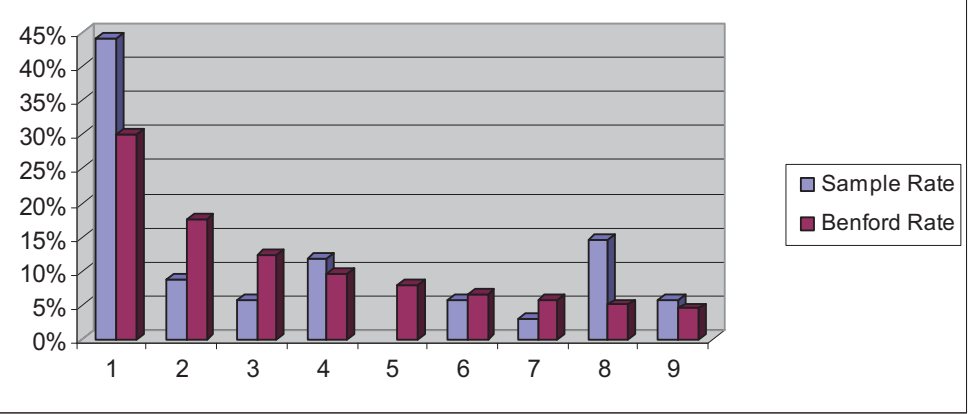

Table 27 Tirana 2009 Electoral 1BL Results

\begin{tabular}{|l|l|}
\hline Group of parties based on 1BL had an increase in votes & Group of parties based on 1BL had a decrease of vote \\
\hline 1 (AD, PAA, AMIE, ADS, PBK, PD, PLL, POSH, PDI, PDK, & 2 (PDM e Re, PBDNJ, G 99) - $8.8 \%$ \\
PRDSH, LSI, PGJ, PSV 91, PDS, PS) 14\% & 3 (PBD, PSD) - $6.6 \%$ \\
4 (PBKD, PDRESH, LZHK, PKONS) 2.1\% & 5 (empty set of data) $-7.9 \%$ \\
8 (BLD, LDK, PRRL, PTR, PLIDR) 9.6\% & 6 (PFA, PR) $-0.8 \%$ \\
9 (LDLNJ, PMDE) 1.3\% & 7 (BLD, LDK, PRRL, PTR, PLIDR) $-2.9 \%$ \\
\hline
\end{tabular}

Tirana is the district with the largest number of parliamentary mandates (32/140) (Electoral Code of Albania, 2008), double of the second largest one Fier with 16/140 legislature mandates. This means that this district has the greatest importance in the parliamentary election process because it has more than $1 / 4$ of the Albanian parliamentary legislature seats. This is the reason why the political parties do focus a lot of energies in this district. For as, Tirana is the main district observed experiencing vote manipulation, as confirmed from the $1 \mathrm{BL}$ vote distribution control measurement. It is on the top of the district list with the greatest oscillations of differences between the normal distribution and 1 digit Benford's Law.

Table 26 shows that all first digit number groups of parties in the Tirana district normal distribution does not correlate to the $1 \mathrm{BL}$ distribution. Moreover, they have a huge difference between them except first digit 6 (two small parties of the Changing Alliance Coalition) and 9 (two smaller Socialist for Integration Alliance parties) which altogether have an increase of about $1 \%$ in vote number. This is not statistically significant as the other first digit number groups with a very large shift in votes.

The highest differences are in first digit group $1(+14 \%), 2(-8.8 \%), 3(-6.6 \%)$ and the five 5 digit group (empty set of votes $-7.9 \%), 7(-2.9 \%)$ and $8(+9.6 \%)$. As it can be seen in table 14, the group that had the largest loss of counted votes is the 2 group which is formed from a small Changing Alliance Coalition party (PDM e Re) and from two Union for Change parties (PBDNJ and G 99).

Interesting is in this case, the G 99 party (a former civil society organization centered in Tirana City) which in this city had a large number of supporters, as part of the in 2 digit group, could be the party that had the largest percentage of votes shift. G 99 party and the others in this group (PBDNJ, PMD e Re) had loss of $-8.8 \%$ of votes, as minimum, one of them could had high potential for getting a parliamentary mandate.

The other two important percentages to analyze are parties that belong to group 3 and 5 . The first is formed from the Albanian Democratic Union Party (Freedom Pole Alliance) and Social Democratic Party of Albania (in coalition with the Socialist Party of Albania in Union for Change Coalition), which have experienced also a loss of votes. The lost votes of this coalition are repeated in group 7 (PTR). The Changing Alliance coalition smaller parties are present in the column of lost counted votes (PFA, PR, BLD, and LDK) but they belong to small loss of votes percentage. Group 5 is an empty data set of votes, what means that this group votes had a total shift of votes towards the parties that based on $1 \mathrm{BL}$ had an increase in votes.

The most increase of votes had group 1, which is formed mostly from Democratic Party of Albania and its coalition parties (AD, PAA, AMIE, ADS, PBK, PD, PLL, POSH,). Interesting in this group is that also the two other largest parties in Albania, Socialist Movement for Integration and Socialist Party belong to the group. This means that all these three main political parties could have done votes manipulation, although the Changing Alliance coalition parties, if we translate their presence in percentage, are more present in the increased number of votes with $44.8 \%$; most probable to have done fraud than the others. However, also the Socialist Movement for Integration small parties in group 8 (PTR) had an increase in votes as well as other smaller parties of the Democratic Alliance are present in this category. 
It can be said that the vote counts distribution of first digits of Benford's Law in Tirana district, doesn't correspond at all to the normal distribution in Tirana real election data. From the above analysis is clear that all the three main parties of Albania, PD, PS and LSI, had a probable significant increase in votes, presenting the opportunity to performed fraud in their interest. Although it can be clearly seen that the Changing Alliance Coalition and its main party PD ${ }^{1}$, probably had the most increase in counted votes.

\section{Conclusions}

First digit Benford's Law has been applied to the 2009 Albanian election official results vote counting, as a way of mapping the disputes for the fraud level during this election count of votes. This form of distribution was applied to each party votes' results for each of the 12 districts for the 2009 parliamentary elections. The results and graphs show that there has been an obvious election fraud because almost in all districts there is no correlation between the real data of counted votes distribution and Benford's distribution rate. There are also a number of district that the 1BL showed the minimum counted vote fraud, partially confirmed in Fier and Gjirokastra districts.

As a conclusion, the analyses performed evidence of shifted votes in Albanian 2009 counted votes. Predominantly the highest to have done manipulation, translated in the most beneficiary of the counted votes increase are the Changing Alliance Coalition, followed from the LSI (both of them are the lead parties of the 2009-13 governmental coalition). Instead the Socialist Party, its coalition of Union for Change, and parties of the Freedom Pole Coalition seem more likely to be on the losing side of votes percentage due to counting manipulations, although the PS and the parties its Union for Change Coalition are also present in some districts as beneficiary of vote numbers.

The vote count fraud based on $1 \mathrm{BL}$ has been done in the interest of the main parties (PD, PS, LSI) as an increase in their rate. In some districts, it appear as a vote manipulation directly in the main parties vote percentage increase while in some other districts it appears as an indirectly increase through the percentage increase of the respectively coalitions smaller parties.

\section{References}

Benford F,T he law of anomalous numbers, Proc Am Philos Soc 78:551-572), 1938

Code of the Republic of Albania, Approved by Law no. 10 019, dated 29 December 2008, and amended by Law no.

74/2012, dated 19 July 2012, pg. 62, http://cec.org.al//images/stories/eng/legiislacion/Electoral\%20Code.pdf, last seen at 25.06.2013)

Deckert J., Myagkov M., and Ordeshook C. P., Benford's Law and the Detection of Election Fraud,

Political Analysis 19:245-268, 2011

Diamond LJ, Plattne MF Electoral Systems and Democracy, Johns Hopkins Univ Press, Baltimore, 2006

Mebane, Jr, Walter R. Election Forensics: Vote Counts and Benford's Law , July 17, 2006, Prepared for presentation at the 2006

Summer Meeting of the Political Methodology Society, University of California-Davis, July 20-22

Judge G., Schechter L., Detecting Problems in Survey Data using Benford's Law,

http://www.aae.wisc.edu/lschechter/benford.pdf, Last seen, November 1, 2007

OSCE/ODIHR, Office for Democratic Institutions and Human Rights, Republic Of Albania Parliamentary Elections, 28 June 2009, OSCE/ODIHR Election Observation Mission Final Report, Warsaw, 14 September 2009

Sambridge M., Tkal'ci'c H. and Arroucau P., Benford's Law on first digits: From Mathematical Curiosity to Change Detector, Asia Pacific Mathematics Newsletter, October 2011, Volume 1 No 4, The Electoral

Stephen Battersby, Statistics hint at fraud in Iranian election, New Scientist, 24 June 2009

The Economist. 2007. Nigeria: How to steal an election. Published April 18, 2007,

http://www.economist.com/node/9032254 (Last see May 12, 2012).

\footnotetext{
${ }^{1}$ Need to be mentioned that the PD was at that time the Government Party from 2005.
} 


\section{Annex}

\section{Table 2812 Albanian District Final Electoral Results percentage}

\begin{tabular}{|c|c|c|c|c|c|c|c|c|c|c|c|c|c|c|c|}
\hline \multicolumn{15}{|c|}{ FINAL ELECTORAL REZULTS OF 12 DISTRICT OF ALBANIA } & \multirow[t]{2}{*}{ Coalition } \\
\hline $\mathrm{Nr}$ & Elective Subjects & Abbr & Dibër & Durrës & Elbasan & Fier & Gjirokastër & Korçë & Shkodër & Kukës & Lezhë & Vlorë & Berat & Tiranë & \\
\hline 1 & Democratic Alliance Party & $A D$ & $0.34 \%$ & $0.24 \%$ & $0.39 \%$ & $0.24 \%$ & $0.42 \%$ & $0.22 \%$ & $0.32 \%$ & $0.84 \%$ & $0.48 \%$ & $0.23 \%$ & $0.20 \%$ & $0.29 \%$ & \multirow{15}{*}{ 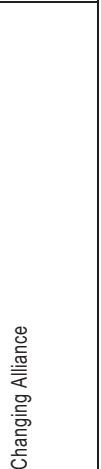 } \\
\hline 2 & Liberal Democratic Union & BLD & $1.34 \%$ & $0.22 \%$ & $0.71 \%$ & $0.05 \%$ & $0.08 \%$ & $0.58 \%$ & $0.10 \%$ & $0.05 \%$ & $0.64 \%$ & $0.06 \%$ & $0.29 \%$ & $0.24 \%$ & \\
\hline 3 & Christian Democratic Union of Albania & LDK & $0.03 \%$ & $0.07 \%$ & $0.05 \%$ & $0.03 \%$ & $0.07 \%$ & $0.17 \%$ & $2.35 \%$ & $0.04 \%$ & $2.13 \%$ & $0.34 \%$ & $0.12 \%$ & $0.21 \%$ & \\
\hline 4 & Environmentalist Agrarian Party & PAA & $0.50 \%$ & $0.35 \%$ & $1.78 \%$ & $1.00 \%$ & $0.27 \%$ & $0.46 \%$ & $2.51 \%$ & $0.43 \%$ & $2.33 \%$ & $0.89 \%$ & $0.13 \%$ & $0.36 \%$ & \\
\hline 5 & $\begin{array}{l}\text { Macedonian for European Integration } \\
\text { Alliance Party }\end{array}$ & AMIE & $0.14 \%$ & $0.02 \%$ & $0.04 \%$ & $0.01 \%$ & $0.01 \%$ & $0.48 \%$ & $0.02 \%$ & $0.07 \%$ & $0.02 \%$ & $0.01 \%$ & $0.02 \%$ & $0.03 \%$ & \\
\hline 6 & Democracy and Solidarity Alliance Party & ADS & $0.05 \%$ & $0.07 \%$ & $0.16 \%$ & $0.06 \%$ & $0.04 \%$ & $0.05 \%$ & $0.28 \%$ & $0.01 \%$ & $0.01 \%$ & $0.03 \%$ & $0.02 \%$ & $0.03 \%$ & \\
\hline 7 & National Front & PBK & $0.01 \%$ & $0.28 \%$ & $0.11 \%$ & $0.39 \%$ & $1.05 \%$ & $0.32 \%$ & $0.57 \%$ & $0.01 \%$ & $0.11 \%$ & $0.79 \%$ & $0.11 \%$ & $0.32 \%$ & \\
\hline 8 & Democratic National Front Party & PBKD & $0.03 \%$ & $0.23 \%$ & $1.06 \%$ & $0.06 \%$ & $0.36 \%$ & $0.10 \%$ & $0.23 \%$ & $0.18 \%$ & $0.89 \%$ & $0.33 \%$ & $0.04 \%$ & $0.11 \%$ & \\
\hline 10 & Democratic Party of Albania & PD & $49.07 \%$ & $45.65 \%$ & $37.19 \%$ & $31.55 \%$ & $35.60 \%$ & $42.14 \%$ & $48.54 \%$ & $58.53 \%$ & $44.25 \%$ & $28.59 \%$ & $26.72 \%$ & $42.48 \%$ & \\
\hline 11 & New Denied Rights Party & PDM e Re & $0.07 \%$ & $0.09 \%$ & $0.08 \%$ & $0.08 \%$ & $0.07 \%$ & $0.18 \%$ & $0.06 \%$ & $0.08 \%$ & $0.28 \%$ & $0.06 \%$ & $0.04 \%$ & $0.08 \%$ & \\
\hline 12 & Forca Albania Party & PFA & $0.04 \%$ & $0.03 \%$ & $0.02 \%$ & $0.02 \%$ & $0.02 \%$ & $0.02 \%$ & $0.02 \%$ & $0.02 \%$ & $0.02 \%$ & $0.02 \%$ & $0.02 \%$ & $0.02 \%$ & \\
\hline 13 & Legality Movement Party & PLL & $3.13 \%$ & $0.50 \%$ & $0.50 \%$ & $1.56 \%$ & $0.07 \%$ & $0.24 \%$ & $0.23 \%$ & $1.36 \%$ & $1.45 \%$ & $0.19 \%$ & $0.09 \%$ & $0.47 \%$ & \\
\hline 14 & Albanian Time Party & POSH & $0.03 \%$ & $0.11 \%$ & $0.05 \%$ & $0.05 \%$ & $0.02 \%$ & $0.03 \%$ & $0.17 \%$ & $0.03 \%$ & $0.03 \%$ & $0.04 \%$ & $0.03 \%$ & $0.03 \%$ & \\
\hline 15 & Party for Justice and Integration & PDI & $0.04 \%$ & $1.48 \%$ & $0.61 \%$ & $2.65 \%$ & $0.06 \%$ & $0.04 \%$ & $0.05 \%$ & $0.03 \%$ & $0.03 \%$ & $4.65 \%$ & $0.12 \%$ & $0.44 \%$ & \\
\hline 16 & Republican Party of Albania & PR & $2.77 \%$ & $2.12 \%$ & $2.12 \%$ & $2.14 \%$ & $1.81 \%$ & $1.77 \%$ & $2.54 \%$ & $2.97 \%$ & $1.51 \%$ & $1.15 \%$ & $5.12 \%$ & $1.61 \%$ & \\
\hline 17 & National Development movement & LZHK & $2.14 \%$ & $0.43 \%$ & $0.24 \%$ & $1.17 \%$ & $0.30 \%$ & $0.28 \%$ & $0.42 \%$ & $0.36 \%$ & $0.21 \%$ & $0.33 \%$ & $0.16 \%$ & $1.17 \%$ & 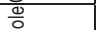 \\
\hline 18 & Albanian Democratic Union Party & PBD & $0.14 \%$ & $0.03 \%$ & $0.04 \%$ & $0.02 \%$ & $0.02 \%$ & $0.02 \%$ & $0.04 \%$ & $0.06 \%$ & $0.13 \%$ & $0.22 \%$ & $0.02 \%$ & $0.09 \%$ & \\
\hline 21 & Conservative Party of Albania & PKONS & $0.07 \%$ & $0.21 \%$ & $0.03 \%$ & $0.01 \%$ & $0.03 \%$ & $0.01 \%$ & $0.06 \%$ & $0.00 \%$ & $0.55 \%$ & $0.13 \%$ & $0.01 \%$ & $0.01 \%$ & \\
\hline 22 & Path of Freedom Party & PRRL & $0.02 \%$ & $0.01 \%$ & $0.03 \%$ & $0.01 \%$ & $0.01 \%$ & $0.02 \%$ & $0.02 \%$ & $0.11 \%$ & $0.56 \%$ & $0.05 \%$ & $0.31 \%$ & $0.02 \%$ & \\
\hline 23 & Movement for Human Rights and Liberties & LDLNJ & $0.07 \%$ & $0.12 \%$ & $0.12 \%$ & $0.08 \%$ & $0.21 \%$ & $0.51 \%$ & $0.05 \%$ & $0.08 \%$ & $0.11 \%$ & $0.34 \%$ & $0.11 \%$ & $0.26 \%$ & \\
\hline 24 & Socialist Movement for Integration & LSI & $5.41 \%$ & $7.28 \%$ & $4.58 \%$ & $6.13 \%$ & $1.93 \%$ & $3.42 \%$ & $2.42 \%$ & $2.78 \%$ & $3.50 \%$ & $3.59 \%$ & $10.84 \%$ & $4.62 \%$ & \\
\hline 25 & Green Party of Albania & PGJ & $0.02 \%$ & $0.03 \%$ & $0.03 \%$ & $0.02 \%$ & $0.02 \%$ & $0.03 \%$ & $0.01 \%$ & $0.00 \%$ & $0.02 \%$ & $0.02 \%$ & $0.02 \%$ & $0.05 \%$ & \\
\hline 26 & $\begin{array}{l}\text { Party for the Defense of the Rights of the } \\
\text { Emigrants }\end{array}$ & PMDE & $0.03 \%$ & $0.02 \%$ & $0.03 \%$ & $0.01 \%$ & $0.03 \%$ & $0.04 \%$ & $0.02 \%$ & $0.00 \%$ & $0.02 \%$ & $0.05 \%$ & $0.01 \%$ & $0.02 \%$ & \\
\hline 27 & True 91 Socialist Party & PSV 91 & $0.17 \%$ & $0.44 \%$ & $0.27 \%$ & $0.21 \%$ & $1.05 \%$ & $0.20 \%$ & $0.39 \%$ & $0.10 \%$ & $1.94 \%$ & $0.97 \%$ & $0.35 \%$ & $0.27 \%$ & \\
\hline 28 & New tolerance Party of Albania & PTR & $0.01 \%$ & $0.13 \%$ & $0.02 \%$ & $0.01 \%$ & $0.03 \%$ & $0.02 \%$ & $0.01 \%$ & $0.01 \%$ & $0.02 \%$ & $0.03 \%$ & $0.01 \%$ & $0.02 \%$ & 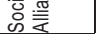 \\
\hline 29 & Unity for Human Rights Party & PBDNJ & $0.30 \%$ & $0.23 \%$ & $0.89 \%$ & $0.30 \%$ & $4.98 \%$ & $1.70 \%$ & $1.07 \%$ & $0.31 \%$ & $0.40 \%$ & $5.72 \%$ & $0.15 \%$ & $0.77 \%$ & $\bar{\square}$ \\
\hline 30 & Social Democracy Party of Albania & PDS & $0.39 \%$ & $0.45 \%$ & $0.40 \%$ & $0.58 \%$ & $1.61 \%$ & $0.49 \%$ & $1.99 \%$ & $0.49 \%$ & $0.34 \%$ & $1.12 \%$ & $1.00 \%$ & $0.43 \%$ & \\
\hline 31 & G 99 Party & G99 & $0.49 \%$ & $0.58 \%$ & $0.76 \%$ & $0.68 \%$ & $1.29 \%$ & $0.68 \%$ & $0.48 \%$ & $0.23 \%$ & $0.50 \%$ & $0.92 \%$ & $4.07 \%$ & $0.68 \%$ & \\
\hline 32 & Social Democratic Party of Albania & PSD & $0.86 \%$ & $0.84 \%$ & $1.60 \%$ & $1.84 \%$ & $1.84 \%$ & $1.32 \%$ & $2.18 \%$ & $10.22 \%$ & $3.19 \%$ & $2.53 \%$ & $1.12 \%$ & $0.95 \%$ & 등 \\
\hline 33 & Socialist Party of Albania & PS & $30.35 \%$ & $37.12 \%$ & $44.12 \%$ & $48.42 \%$ & $46.19 \%$ & $43.63 \%$ & $29.46 \%$ & $20.06 \%$ & $30.03 \%$ & $44.60 \%$ & $48.28 \%$ & $42.85 \%$ & 50 \\
\hline 34 & Law an Justice Party & PLIDR & $0.10 \%$ & $0.26 \%$ & $0.18 \%$ & $0.17 \%$ & $0.13 \%$ & $0.42 \%$ & $0.36 \%$ & $0.05 \%$ & $2.23 \%$ & $0.19 \%$ & $0.19 \%$ & $0.21 \%$ & $=\stackrel{\overline{\bar{m}}}{=}$ \\
\hline 35 & Abdullah Adil Omuri & & & & & & & & & & & & & $0.20 \%$ & \\
\hline
\end{tabular}

